\title{
Expert Method of Quality Management of Road Construction Project
}

\author{
S.S. Achilov \\ Senior Teacher, Candidate of Economical Science, Samarkand Branch of Tashkent University of \\ Information Technology
}

\begin{abstract}
:
The quality and reliability of construction is one of the cornerstones of the effective development of any investment in the real sectors of the economic life of the country. Solving the problem of road construction quality requires a comprehensive approach to project management, as well as the maximum requirement of the principles and rules of construction from the customers of the projects. The article considers one of the new and unconventional approaches to solving the urgent problem of road construction, associated with the expert assessment and maintenance of the required level of road quality, which will lead to qualitative changes in the life of the city's population.
\end{abstract}

\section{Introduction}

Organizers and developers of technical projects of road construction envisage a system of quality management of road construction of the main effective methods. The quality of construction is the development of effective and transparent investments in the real economy is one of the cornerstones. According to international project standards «PMBoK» (Project management body of knowledge (eng.Project Management Body of Knowledge, PMBoK)) and a number of other national and international standards, the goal of any project is to meet the requirements of the project customer. This goal is achieved by ensuring quality management and the final result of this project. Quality is a synthetic indicator reflecting the cumulative manifestation of various factors of a given process. It is known that the main indicators that reflect the quality of any project are: purpose, reliability, manufacturability, standardization, unification, safety, etc. The quality of road construction work is evaluated on the basis of quantitative measurement of its determining characteristics, where the final product is a road with a complex of various auxiliary structures and devices. As a general concept, the quality of the road should be understood as a set of properties that determine its suitability to meet the needs of the public economy in freight and passenger traffic, loads and intensity of traffic at minimum cost as well as providing a comfortable space and safe movement of the population in the city.

It should be emphasized that, in recent years, innovative methods and high quality materials have been successfully used in the construction of roads in the cities of Uzbekistan. Road construction design processes are accompanied by regular scheduled inspections by the appropriate organizations to determine the compliance of the work with all regulatory requirements. In this case, these organizations monthly report to the customer on the progress of the design work as well as drawing up an act of acceptance of operation of the construction road. Only strict compliance with the rules of the works and the specified technological process can be ensured by the production discipline of all participants in the project. However, it is not clear why observing all the normative rules and technology of road construction, the output is not qualitative roads, in particular in the city of Samarkand (Republic of Uzbekistan). The question arises why our city roads are so fundamentally different in quality, durability and size of space and convenience for citizens from their foreign 
counterparts at the time of operation. Based on the above critical evaluations, we propose a comprehensive and effective "bottom-up" approach, namely management and quality control of road construction works on the basis of methods of expert evaluations on the example of Samarkand. The essence of the method lies in the fact that initially, after the development of design documentation of road construction projects, it is necessary that it has passed all stages of state examination according to the schedule. After that, during the entire life cycle of construction, to assess and analyze the quality of road construction works should participate competent specialists - independent construction experts. Statistical processing of the final results of road construction obtained from the expert scores confirms that expert methods are the most effective and optimal tools to determine the quality indicators of road construction[1].

The global construction industry is currently undergoing a fundamental transformation. There is a transition from traditional methods of design with the preparation and subsequent use of design documentation to the use of information modeling of buildings and structures. This makes it possible to form design, estimate and performance documentation as a single information resource for the object throughout its life cycle, including the stages of operation and decommissioning. Therefore, solving the problem of road quality construction requires a comprehensive and systematic approach to project management throughout the life cycle with the widespread use of modern information and technological technologies (ICT). However, the prospects for the development of information technology in construction and, in particular, the road sector, at the level of international standards are still disappointing. And even those various automated systems that are used today in the construction complex of Uzbekistan, do not meet modern requirements: they, for example, do not provide for the implementation of the social orientation of the population and consumer protection. And this is one of the priorities of the reform of urban planning. Most of the implemented systems do not provide a dynamic adjustment to the constantly changing legislation and regulations and do not provide, say, transparency of the entire life cycle of road construction. Experts assess the level of development of information technology in the road construction industry as - low, in many regions of the Republic of Uzbekistan such technologies are absent at all, the information about the condition of roads is not structured.

This negative situation hinders the introduction of the world's most advanced information systems in construction. Therefore, according to many experts, this sphere of society is in crisis, which is historically conditioned by a number of circumstances:

$>$ inefficient management system,

$>$ high material expenses,

$>$ underdeveloped competitive environment,

$>$ chronic non-payments.

Among the problems that must be solved in the implementation of construction reform, a special place is the reliability and availability of information, as well as the transition process of reforming into a qualitatively new market state. This problem can be solved successfully only on the basis of advanced information technology. The introduction of modern information technology will create a qualitatively new system of urban and district construction management, as well as a system of regulated interaction with the executive bodies of state power. Modern information technology should provide monitoring of the state of the building stock, engineering networks and road communications, control of payments for work performed, as well as informational support for the management decision-making process. Consequently, the systematic use of modern ICT in the management of road construction works will lead to qualitative changes in the life of the population, and will seriously improve the quality, speed and transparency of road construction monitoring in 
Uzbekistan. To date, the republic is gradually automating all areas of construction activities, as well as their accounting for all types of services. Systematic introduction of web-portals - construction portal of Uzbekistan (stroyka.uz), open data portal (data.gov.uz) and normative-legal act (regulation.gov.uz), etc. is an example, providing mechanisms of openness, transparency and feedback from the population by the state. The unified online information portal will allow, at the first stage, to make available information about the state of road construction in real time.

Thus, today's global digital economy is radically changing the way we think about familiar things. New terms and methods are emerging that can best explain the processes taking place. More recently, the term " automobile road" has been defined as "an engineering structure designed for automobile traffic. The peculiarity of the new technological revolution lies in the engineering and socio-economic integration of related systems. Today, a highway is a centralized transport infrastructure facility designed for the movement of various vehicles. At one time the object of study in the road industry was: driver - car - road, today it is a system: people - loads - traffic flows transport infrastructure - digital economy. Key technologies that ensure the digitalization of the road sector - information modeling (BIM - Building Information Modeling) and intelligent transportation systems (ITS- Intelligent transportation system). Technology BIM information modeling affects mainly the activities of traffic engineers, ITS serve as a digital tool, especially for automotive and transportation engineers. Consequently, the junction of these two areas of activity can provide, in the language of IT specialists, the integration bus "Digital automobile road. [4,10,11]. Therefore, digitalization in road construction is still the subject of much discussion and debate among specialists.

Solving the problem of construction quality requires a comprehensive approach to project management, with priority on the requirements of project customers. Currently, an important criterion for the effectiveness of road construction is a functional platform, i.e full automation of the entire cycle of work processes. Transparency in the expenditure of planned funds is achieved with the help of the module of control of works on commitments, which implies the confirmation of the work through the system by photo, video recording and other control tools, according to which the expenditure item, it becomes possible to control the expenditure of funds at each stage of work. In addition, you can make various statistical calculations on the actual work performed for the project manager.

Contractors should also have access to the platform. They must also be able to control the process of production work. One of the most important tools of control is a mobile application, through which the contractor can receive tasks and send photos and videos to the system, confirming the fact that the work is done. In fact, contractors can use such solutions for their own needs as well, for example, in the case of the need for internal control of employees. In terms of technology, the system should be based on a registry that contains all the information on objects, contracts, performers and the current state of the road network facilities. And this is one of their main and key advantages, which increases the transparency and quality of road works.

However, compliance with regulatory and technological requirements for road construction is not a guarantee of their proper quality. In road construction, a rather complex system of evaluating the compliance of work performed with the project and the quality of the pavement is used. This reduces the durability of urban roads and increases their cost. As it is known, the city of Samarkand is scheduled to host a summit of heads of states members of the Shanghai Cooperation Organization in 2022. As part of preparations for the summit, the city of Samarkand was allocated a loan of $\$ 25$ million for the purpose of improving the condition of internal roads. The efficiency of the use of these credit funds is connected, among other things, with the quality of road construction works. In our opinion, it is necessary to improve the system of internal road construction project management 
by attracting a wide range of independent and competent specialists and experts.

Technical control is a set of methodological guidelines for determining the quality parameters of roads, materials used, technological processes and finished products and their comparison with the requirements of technical specifications and standards. Systematic scheduled technical control allows for more effective management of the quality of road construction in the city. However, for some reason, complying with all regulatory rules and technology of the construction process, at the time of operation, the urban roads of Uzbekistan radically differ in quality, durability from their foreign counterparts and standards. As a result, it turns out that either our technologies and standards for road construction are much outdated, or simply not suitable for our climatic latitudes, or most importantly, corrupt structures are successfully involved in co-production of project documentation or tenders. In this case, in the construction of roads, corruption, figuratively speaking, participates invisibly, it is very difficult to detect. Meanwhile, corruption in road construction can be detected only after a very thorough and objective analysis. Here, we agree that the main problem is the inordinate appetite of corrupt officials who make money from road construction by lobbying the interests of other competitive companies. As a result, the cost of completed road construction work increases, and the quality is very different from the normative readings. The most important aspect of the road is the consideration of its actual value and the duration of its operation. Therefore, we offer an optimal and effective bottom-up approach to the management and quality control of the entire life cycle of road construction works. The essence of the method is as follows: first, after the development of project documentation of road construction works, it is necessary that it has passed the state expertise, according to the regulations on construction. After the bidding (tender), usually an electronic auction, the project organization - the winner (Contractor) proceeds to the implementation of the project for the construction of roads. Further, to assess and analyze the quality of the process of road construction works must involve competent construction specialists - experts. A sample expert survey is conducted in all phases of road construction work:

$>$ in the process of developing design and estimate documentation;

$>$ to assess the quality of raw materials, materials and workmanship;

$>$ during construction and installation work;

$>$ in the operational phase of the roads.

From the above it can be assumed that the proposed new bottom-up approach is an effective, operational and efficient method of managing and assessing the quality of road construction. The main purpose of the bottom-up method is to integrate all major road construction processes into a single quality management plan called "plan - control - cost" based on expert evaluation methods. Each stage of the completed road construction work should be an amalgamation of all the important parts of the whole project. In selecting management strategies and quality assurance, construction roads of the city Contracting Organization is guided by the approved design and estimate documentation and the project of works. The design of the work ensures the efficiency and focus of all organizational, technical and technological solutions to achieve the final result, with the required quality, within the specified time frame, with the minimum cost.

Managing and controlling the quality of roads is a complex, scientific, technical, economic and social problem. The output of road construction products has a significant specificity, since road construction involves design and survey, production, procurement, construction and installation, subcontracting, maintenance and other organizations that are separated territorially and administratively. Therefore, the project must represent a unified chain, ranging from individual local organizational and technical measures to continuous activities within the framework of large construction organizations. Consequently, the quality of the road, should be considered at different 
levels, aimed at meeting certain production, economic and social requirements. It is important, when carrying out road construction work in cities and towns must comply with the requirements of comfort and safety of roads adjacent areas. Therefore, the proposed expert method is used when road quality indicators cannot be determined due to insufficient reliable information and the impossibility or inexpediency under specific conditions of assessment, as well as avoidance of the abovementioned negative consequences.[2,7].

Currently, the expert method of quality assessment and control, construction roads in project management is a scientifically sound method of analyzing complex problems that are not formalized. The expert is the repository of a large amount of objective and rationally processed information and can therefore be regarded as a quality source. The group opinion of experts (more than 15 experts) is close to the true solution to the problem. The main varieties of peer review method include: questionnaire, interviewing, brainstorming, discussion, meeting, operative game and scenario. Each of these methods of expert evaluation has its own advantages and disadvantages, determining the rational area of application. To build survey procedures and data processing algorithms, methods of measurement theory and mathematical statistics are usually used. The resulting statistical processing generalized judgment of the experts is taken as a solution to the problems. In the practical use of the expert method to assess the quality of roads, a working and expert group is formed. The working group organizes the procedure for interviewing experts, collects questionnaires, works out and analyzes expert evaluations. The expert group is formed from highly qualified and competent professionals in the field of construction works. It is very important that the expert group is not formed for a single examination, but as a permanently functioning body with a stable composition of experts.

A scientifically based system of expert interviews is required to obtain reliable results. The processing of the data received from the experts serves as a source material to confirm the reliability, durability and quality of operation of construction roads. The article also shows that in order to maximize the effectiveness of construction roads quality, it is necessary to establish a quantitative or point scale for all used indicators of the quality of work. Then the sum of points of each factors and the total amount of points is determined. Then the weighting coefficients of the points of each factor are evaluated and the results are checked by summation. The following is an example where a questionnaire for a survey of competent experts on the quality of road construction in Samarkand for the year 2020 is compiled. The questionnaire consists of 5 questions, and the answers of experts (more than 15) are recorded on a 10-point scale for all expert members participating in the survey (1min score, 10-max score).

The questionnaire includes the following topical issues of road construction in the city:

1. Reliability and safety of the road and pedestrian road;

2. The convenience and comfort of the pedestrian road space;

3. Creation of parks and boulevards, taking into account the parking zones of roads;

4. The level of improvement and landscaping of roads, taking into account the design of the city;

5. Environmental friendliness and quality of the road, taking into account local climatic and natural conditions.

Table.1. Expert scoring of factors

\begin{tabular}{|c|c|c|c|c|c|c|c|c|c|c|c|c|c|c|c|c|}
\hline Experts & 1 & 2 & 3 & 4 & 5 & 6 & 7 & 8 & 9 & 10 & 11 & 12 & 13 & 14 & 15 & Total \\
\cline { 1 - 16 } Factors & & & & & & & & & & & & & & & & 55 \\
\hline 1 & 3 & 4 & 4 & 3 & 4 & 3 & 4 & 4 & 4 & 4 & 3 & 4 & 3 & 4 & 4 & 55 \\
\hline
\end{tabular}




\begin{tabular}{|c|c|c|c|c|c|c|c|c|c|c|c|c|c|c|c|c|}
\hline 2 & 2 & 3 & 3 & 4 & 3 & 2 & 3 & 4 & 4 & 3 & 4 & 3 & 4 & 4 & 4 & 50 \\
\hline 3 & 4 & 3 & 2 & 5 & 4 & 3 & 4 & 4 & 3 & 4 & 3 & 4 & 3 & 4 & 4 & 54 \\
\hline 4 & 4 & 2 & 3 & 4 & 3 & 4 & 3 & 4 & 3 & 4 & 3 & 4 & 4 & 3 & 4 & 52 \\
\hline 5 & 3 & 3 & 4 & 4 & 3 & 4 & 2 & 4 & 3 & 4 & 3 & 4 & 3 & 5 & 3 & 52 \\
\hline Total & 16 & 15 & 16 & 20 & 17 & 16 & 16 & 20 & 17 & 19 & 16 & 19 & 17 & 20 & 19 & 263 \\
\hline
\end{tabular}

The final quantitative assessment of the factor is determined using the method of simple ranking, the data are shown in Table 1. Using the method of mathematical statistics, we obtain a generalized expert opinion. The average rank of each factor, the average statistical value of the $\mathrm{Sj}$-th factor is determined.

$$
S_{j}=\frac{\sum_{i=1}^{15} a_{i j}}{m_{j}}
$$

where $S_{j}$ is the average value of the factors,aij is the expert's evaluation of the factor.mj - number of experts evaluating the $\mathrm{j}$-th factor, $\mathrm{i}$ - number of the expert,

$\mathrm{j}$ - number of the factor. After processing the data in Table 1, the average rank of the factors was: $\mathrm{S} 1=3,7 ; \quad \mathrm{S} 2=3,3 ; \quad \mathrm{S} 3=3,6 ; \quad \mathrm{S} 4=3,5 ; \quad \mathrm{S} 5=3,5 ;$

Based on the results of the expert scoring, we can conclude that the overall expert opinion on the quality and reliability of road construction in Samarkand is below the average standard, i.e at an unsatisfactory level. Consequently, the planned level of quality of road construction must be balanced with the amount of consumer demand, determined by the actual solvency of potential customers. As a result, we can recommend that Uzbekistan should be updated, at the legislative level, standards and urban planning norms and regulations in the field of landscaping on the basis of foreign analogues. On this basis, it is proposed that the following requirements and recommendations should be included in urban road construction projects, as well as in national regulatory methodologies and international standards:

$>$ introduction of qualitatively new principles and rules of organization of road construction works on the basis of foreign analogues;

$>$ creating a comfortable and safe space for people;

$>$ organization of parking zones for cars and passenger vehicles;

$>$ established requirement for public transport stops, kiosks and other non-stationary objects;

$>$ Improvement of approaches to the integrated arrangement of sections of of highways with pedestrian and bicycle lanes taking into account best international practices;

$>$ the order of landscaping of the territory, taking into account the complex design regional climatic and natural conditions of the city;

$>$ the level of amenities and the impact on the ecology of the area according to national and international standards;

$>$ Improvement of the road network condition management system of roads to increase the efficiency of capital investments, as well as to increase the transparency of project documentation and reduce the timeframe for increasing the transparency of project documentation and reducing the timeframe for road construction;

$>$ implementation in the engineering and management processes of construction information modeling technologies, as well as the motivation of their participants; 
supporting the development of national innovation enterprises that develop digital infrastructure, platforms and technologies;

$>$ potential integration with different solutions, including those with national specifics, using modern SAD-BIM products.

$>$ development of methodological recommendations for assessing the effectiveness and monitoring the organization of road works, taking into account the available in the region resource supply available in the region;

Summarizing the above, we can assume that the current construction industry in Uzbekistan has good potential for digitalization. The gradual transition to digital for economic reasons is overdue: despite many unfavorable factors, a significant number of the most progressive construction companies are adopting new technologies in their work, seeing their high potential and efficiency. Moreover, there are developers in the country capable of creating world-class software, proving the quality of their products by the high effect of implementation. Therefore, the work on "legalization" of information modeling technologies, which has now begun at the state level, has a great chance of success. And, judging by the promulgated government plans, the Uzbek construction industry will finally enter the "digital era" in the next few years [13].

To summarize, we can say that the expert method is the best and most effective tool for managing the quality of road construction projects. Therefore, the expert method should be used as one of the new and non-standard approaches to solving the pressing problem of the construction of the city's road production, which will lead to qualitative changes in the lives of the city's population. Consequently, only a comprehensive bottom-up approach based on expert assessment methods, as well as the systematic use of modern ICT in road construction management will seriously improve the quality, speed and transparency of road construction monitoring in Uzbekistan and is a determining criterion for the effectiveness and durability of their operation.

\section{Reference:}

1. Achilov S.S., Usmonov I.A. "Quality assurance in the management of road construction projects". Problems of architecture and construction (scientific and technical journal). Samarkand, 2019, №-4, 1-part, p.127-130.

2. Beshelev S.D., Gurvich F.G. Mathematical-statistical methods of expert evaluations, 2nd ed. revised and supplemented.-M.: Statistics, 1980.- p.263.

3. V.N. Boykov. SAD roads-development prospects // SAD and GIS automobile road.2013.№1(1). p.6-9.

4. V.N. Boykov, G.A. Fedotov, V.I. Purkin. Automated road design (in the example of IndorCAD/Road). - Moscow:pub.house. MADI(STU), 2005. - p.224 .

5. N.V. Vishnyakov, V.I. Adashkevich, O.V. Gurban, M.S. Timoshenko, N.I. Shishko. Methodical guide. «SAD automobile road (PART 1 )»- M:BNTU, 2014. - 76 p.

6. Mishin V.M. Quality management, Textbook, 2nd ed. revised and supplemented.M:YUNITY,2005.- p.463 .

7. Quality management. Textbook, ed. by. S.D. Ilyenkova., 3rd ed. revised and enlarged., M:YUNITY-DANA, 2012 . p352.

8. Expert evaluations in scientific and technical forecasting / G.M. Dobrov, Y.V. Ershov, E.I. Levitin, L.P. Smirnov. - Kiev: Naukova dumka, 1974. - p.160 .

9. Purkin V.I. Fundamentals of automated road design. - M.:MADI, 2000. - p.141 . 
10. Skvortsov A.V., Sarychev D.S. Life cycle of road projects in the context of information modeling // SAD и GIS automobile road. 2015. № 1(4). p. 4-14.

11. G.A. Fedotov, P.I. Pospelov. Surveying and road design. Book 1-2: Textbook. - M.: High School., 2009. - p.646 .

12. Shashkova I.G., Bishov N.V., Lunin E.V., Konkina V.S., Yagodkina E.I..

Information technologies in transport: Textbook. - Ryazan:

FGBOU VPO RGATU, 2014. - p.298 .

13. National review of housing and land use in Uzbekistan. Country reviews. UN. New York and Geneva, 2015 , p.156.

Website: http://www.unece.org.E-mail: info.ece@unece.org 